\title{
NITROGEN ADDITIONS AND LITTER DECOMPOSITION: A META-ANALYSIS
}

\author{
M. KNORR, ${ }^{1}$ S. D. Frey, ${ }^{1,3}$ AND P. S. Curtis ${ }^{2}$ \\ ${ }^{1}$ Department of Natural Resources, University of New Hampshire, Durham, New Hampshire 03824 USA \\ ${ }^{2}$ Department of Evolution, Ecology, and Organismal Biology, Ohio State University, Columbus, Ohio 43210 USA
}

Abstract. We conducted a meta-analysis of previously published empirical studies that have examined the effects of nitrogen $(\mathrm{N})$ enrichment on litter decomposition. Our objective was to provide a synthesis of existing data that comprehensively and quantitatively evaluates how environmental and experimental factors interact with $\mathrm{N}$ additions to influence litter mass loss. Nitrogen enrichment, when averaged across all studies, had no statistically significant effect on litter decay. However, we observed significant effects of fertilization rate, site-specific ambient $\mathrm{N}$-deposition level, and litter quality. Litter decomposition was inhibited by $\mathrm{N}$ additions when fertilization rates were 2-20 times the anthropogenic $\mathrm{N}$ deposition level, when ambient $\mathrm{N}$ deposition was $5-10 \mathrm{~kg} \mathrm{~N} \cdot \mathrm{ha}^{-1} \cdot \mathrm{yr}^{-1}$, or when litter quality was low (typically high-lignin litters). Decomposition was stimulated at field sites exposed to low ambient $\mathrm{N}$ deposition $\left(<5 \mathrm{~kg} \mathrm{~N} \cdot \mathrm{ha}^{-1} \cdot \mathrm{yr}^{-1}\right)$ and for high-quality (low-lignin) litters. Fertilizer type, litterbag mesh size, and climate did not influence the litter decay response to $\mathrm{N}$ additions.

Key words: litter decay; litter quality; meta-analysis; $N$ addition and litter decay; nitrogen deposition; nitrogen fertilization.

\section{INTRODUCTION}

Nutrient cycling in terrestrial ecosystems is critically dependent on decomposition of plant litter, and extensive research has been done to quantify, model, and predict decomposition rates across a range of ecosystem types. Climate, litter chemistry, and external nitrogen $(\mathrm{N})$ availability all interact to determine decomposition and nutrient-cycling dynamics. Litter-quality parameters, particularly initial lignin and $\mathrm{N}$ contents, often correlate with rates of litter mass loss (Aber and Melillo 1982, Melillo et al. 1982). Thus, ratios of $\mathrm{C}: \mathrm{N}$ and lignin: $\mathrm{N}$ have commonly been used to predict litter decay dynamics (Aber and Melillo 1982, Parton et al. 1987, Taylor et al. 1989, Aber et al. 1990). These ratios also influence the $\mathrm{N}$ dynamics of decaying plant material (Aber and Melillo 1982). While the correlation between initial litter $\mathrm{N}$ content and decay rate has been observed in numerous studies, the relationship between decomposition and external $\mathrm{N}$ availability is less clear. Several studies have reported significantly faster decay rates in response to increased external $\mathrm{N}$ availability (Hunt et al. 1988, Hobbie 2000, Carreiro et al. 2000, Hobbie and Vitousek 2000). However, many others have reported either no significant change (McClaugherty et al. 1987, Pastor et al. 1987, Hunt et al. 1988, Prescott 1995, Bryant et al. 1998, Carreiro et al. 2000, Hobbie and Vitousek 2000) or a suppression of

Manuscript received 27 January 2005; revised 12 July 2005; accepted 19 July 2005. Corresponding Editor: K. T. Killingbeck.

${ }^{3}$ Corresponding author. E-mail: serita.frey@unh.edu decay rates (Magill and Aber 1998, Carreiro et al. 2000).

The differential response to $\mathrm{N}$ additions across studies can be explained in part by differences in litter chemistry. High levels of external N generally stimulate the decay of plant tissues containing low concentrations of lignin and other recalcitrant compounds, while reducing mass loss for high-lignin materials (Berg 1986, Fog 1988, Berg and Matzner 1997, Carreiro et al. 2000, Sinsabaugh et al. 2002, Dijkstra et al. 2004). Sinsabaugh et al. (2002) proposed that N enrichment alters microbial decay by uncoupling the degradation of polysaccharides and polyphenols. This hypothesis is supported by the observation that high $\mathrm{N}$ availability stimulates cellulolysis and suppresses the activity of lignin-degrading enzymes (Carreiro et al. 2000, Sinsabaugh et al. 2002, Frey et al. 2004). While litter quality clearly influences the litter decay response to $\mathrm{N}$ fertilization, other factors, including both environmental conditions (e.g., climate, ambient N-deposition level) and aspects of experimental design (e.g., fertilizer type, litterbag mesh size), may be important in explaining the large differences in both magnitude and direction of the decay response observed in the literature.

Our objective was to conduct a meta-analysis of existing data from previously published $\mathrm{N}$-addition studies to provide a comprehensive and quantitative synthesis of the conditions under which $\mathrm{N}$ enrichment stimulates or inhibits litter decay. Meta-analysis offers formal statistical methods for comparing and integrating the results of multiple studies (Hedges and Olkin 
1985). This approach has been used by ecologists to analyze field competition experiments (Gurevitch et al. 1992), the effects of forest management on soil $\mathrm{C}$ and $\mathrm{N}$ storage (Johnson and Curtis 2001), the response of soil respiration and $\mathrm{N}$ mineralization to experimental ecosystem warming (Rustad et al. 2001), and elevated $\mathrm{CO}_{2}$ effects on plant biomass, reproduction, leaf litter chemistry, and leaf gas exchange (Curtis and Wang 1998, Norby et al. 2001, Jablonski et al. 2002). In the present paper, we evaluated how study type (field experiments vs. laboratory incubations), fertilizer rate and type, site-specific ambient $\mathrm{N}$-deposition level, litter quality, litterbag mesh size, length of the decay period, and climate influence the litter decay response to $\mathrm{N}$ additions.

\section{Methods \\ Data collection}

We reviewed over 900 litter-decomposition studies published since 1980 and identified 24 of these studies where external $\mathrm{N}$ availability was experimentally manipulated in the laboratory or in the field (Appendix A). While many of these studies derived from longterm $\mathrm{N}$-addition experiments where numerous ecosystem properties were measured (e.g., plant biomass, plant community composition, nutrient transformations, soil chemistry), we focused our attention on how $\mathrm{N}$ enrichment influenced litter decay. To be included in our analysis, experimental studies had to report litter mass loss (i.e., not root material or soil organic-matter loss) over the study period for control and $\mathrm{N}$-addition treatments. All studies except one reported percentage litter mass remaining over time. For Carreiro et al. (2000), percentage mass remaining was calculated from reported decay rate coefficients using the single negative exponential decay function: $\log _{e}$ [remaining mass/ initial mass $]=-k t$ (Olson 1963). In a few instances, study authors were contacted if pertinent information was missing (e.g., initial litter composition). Data Thief software (Bas Tummer, Eindhoven, The Netherlands) ${ }^{4}$ was used to extract data from figures.

The experimental field sites were located in grassland, forest or tundra ecosystems in nine countries (Australia, Canada, India, New Zealand, Norway, Scotland, Spain, Sweden, and the United States). Levels of $\mathrm{N}$ fertilization ranged from 24 to $600 \mathrm{~kg} \mathrm{~N} \cdot \mathrm{ha}^{-1} \cdot \mathrm{yr}^{-1}$. Ambient $\mathrm{N}$ deposition at the study sites ranged from $<1$ to $19 \mathrm{~kg} \mathrm{~N} \cdot \mathrm{ha}^{-1} \cdot \mathrm{yr}^{-1}$. Mean annual temperature ranged from $-4.5^{\circ}$ to $24^{\circ} \mathrm{C}$ and mean annual precipitation from 310 to $2500 \mathrm{~mm}$. More than 20 different litter types were represented (Appendix A). Litter decay was followed for periods of $<1$ month to 72 months. Additional site characteristics are given in Appendix B.

\footnotetext{
${ }^{4}$ 〈http://ioc.unesco.org/oceanteacher/resourcekit/M3/ Toolbox/datathief.htm $\rangle$
}

\section{Meta-analysis}

An effect size for each observation was calculated as the natural $\log$ of the response ratio $r=x_{\mathrm{t}} / x_{\mathrm{c}}$, where $x_{\mathrm{t}}$ is the mean for an $\mathrm{N}$-addition treatment and $x_{\mathrm{c}}$ is the mean of the associated unfertilized control (Gurevitch and Hedges 1993). Most of the studies used in this analysis did not provide a measure of variance for the response variable, thus an unweighted meta-analysis was used. The data were analyzed using MetaWin version 2.0 software (Rosenberg et al. 1997). This procedure is analogous to the partitioning of variance in a standard analysis of variance where total heterogeneity for a group of comparisons $\left(Q_{\mathrm{T}}\right)$ is partitioned into within-group $\left(Q_{\mathrm{w}}\right)$ and between-group $\left(Q_{\mathrm{b}}\right)$ heterogeneity. The $Q$ statistic follows a chi-square distribution with $k-1$ degrees of freedom, with $k$ referring to pairs of means and not separate publications (Hedges and Olkin 1985).

In addition to examining the overall effect of $\mathrm{N}$ additions on litter decay, an important goal of our study was to determine whether particular environmental or experimental conditions elicited quantitatively different responses to $\mathrm{N}$ fertilization. The data were grouped according to study type: field experiment or laboratory incubation. Each litter type was placed a priori into one of three litter-quality categories (low, intermediate, high) based on initial nutrient and lignin concentrations, with lignin being the primary determinant. Litters with $<10,10-20$, or $>20 \%$ lignin were placed into the high, intermediate, and low litter-quality categories, respectively. In some cases, the same litter type was placed in more than one quality category if reported litter nutrient concentrations differed due to site-specific differences in soil fertility. For example, Metrosideros polymorpha litter collected from several sites in Hawaii (Hobbie 2000) had similar N contents (0.23$0.33 \%)$, but differed considerably in lignin content $(10-28 \%)$ and thus fell into either the intermediate or low quality category. For the few studies where litter chemistry was not reported, we assigned litter to a quality category based on published literature values for that litter type. Studies were further categorized based on the period over which decomposition occurred $(<6$, $6-12,13-24,>24$ months), litterbag mesh size $(<1$ or $\left.>1 \mathrm{~mm}^{2}\right)$, amount of ambient $\mathrm{N}$ deposition received annually $\left(<5,5-10\right.$, and $\left.>10 \mathrm{~kg} \mathrm{~N} \cdot \mathrm{ha}^{-1} \cdot \mathrm{yr}^{-1}\right)$, level of $\mathrm{N}$ fertilizer applied $\left(<75,75-125,>125 \mathrm{~kg} \mathrm{~N} \cdot \mathrm{ha}^{-1} \cdot \mathrm{yr}^{-1}\right.$ for both field and lab studies; $<5,5-10,11-20,>20$ times ambient $\mathrm{N}$ deposition for field studies only), and type of $\mathrm{N}$ fertilizer applied. Fertilizer types included $\mathrm{KNO}_{3}, \mathrm{Ca}\left(\mathrm{NO}_{3}\right)_{2}, \mathrm{NaNO}_{3}, \mathrm{NH}_{4} \mathrm{NO}_{3}, \mathrm{NH}_{4} \mathrm{SO}_{4}$, urea, and $\mathrm{NH}_{4} \mathrm{NO}_{3}$ plus urea. Several fertilizer types were used in only one study (i.e., $\mathrm{NaNO}_{3}, \mathrm{Ca}\left(\mathrm{NO}_{3}\right)_{2}$, and $\mathrm{KNO}_{3}$ ) and thus were automatically excluded from this aspect of the analysis (i.e., $k<2$; see below). Precipitation categories were $<500,500-1000$, and $>1000 \mathrm{~mm} / \mathrm{yr}$. Levels of mean annual temperature corresponded to

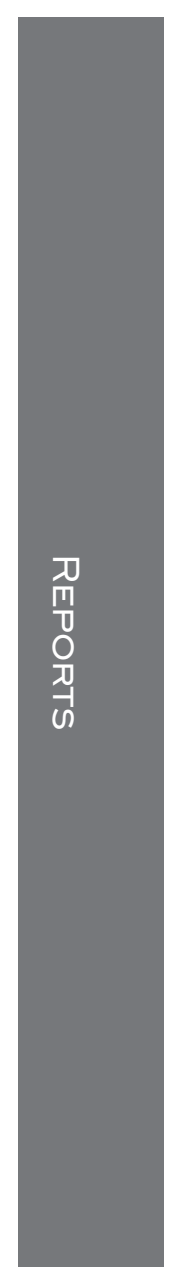


frigid $\left(<8^{\circ} \mathrm{C}\right)$, mesic $\left(8-15^{\circ} \mathrm{C}\right)$, and thermic $\left(>15^{\circ} \mathrm{C}\right)$ temperature regimes. Studies differed in numerous ways in addition to these selected variables, such as among soil textures, vegetation types, and biomes (see Appendices A and B). Partitioning effect sizes according to these variables was not done, either because insufficient data were available to accurately categorize studies (e.g., among soil textures) or because too few studies were present representing a given category to be statistically useful (e.g., among biomes). Given the available information, there are no discernible biases in how the data are distributed across subdivisions within categorical variables (Appendix C). The data in most subdivisions derive from a range of sites, climatic regimes, and vegetation types.

Variance among categorical groups was partitioned to determine the effect of each category (e.g., temperature regime) on percentage litter mass remaining. Categorical subdivisions could only be compared if they were represented by at least two separate studies (e.g., if $k \geq 2)$. Between-group heterogeneity $\left(Q_{\mathrm{b}}\right)$ for each categorical variable was determined for the response variable. If none of the categorical groups displayed significant $Q_{\mathrm{b}}$, there was no statistical justification for further subdivision of the data. Where significant $Q_{\mathrm{b}}$ was observed, the data were subdivided according to levels of those categorical variables with a significant

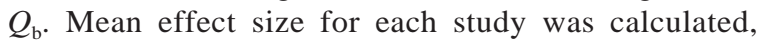
with bias-corrected 95\% confidence intervals (CI's) generated by a bootstrapping procedure using the MetaWin software. Means were considered to be significantly different from zero if the $95 \%$ confidence interval did not overlap zero, and significantly different from one another if their $95 \%$ confidence intervals were non-overlapping (Gurevitch and Hedges 1993, Johnson and Curtis 2001).

\section{Results AND Discussion}

Our meta-analysis is the first quantitative synthesis of the published literature describing the litter decay response to external $\mathrm{N}$ additions. Five hundred observations from 24 studies were included in our analysis. Field experiments and laboratory incubations contributed $77 \%(k=386)$ and $23 \%(k=114)$ of the observations, respectively (Appendix A). The litter decay response to $\mathrm{N}$ additions ranged from a $38 \%$ inhibition to $64 \%$ stimulation (Fig. 1). There was a strong positive relationship, expressed as percentage mass remaining, for litter decay in control compared to fertilized treatments, with the strength of the relationship having an $r^{2}=0.84$. Nitrogen enrichment, when averaged across all 24 studies and 9 categorical variables, had no statistically significant effect on litter decay (Fig. 2a). Between-group heterogeneity $\left(Q_{\mathrm{b}}\right)$ for study type (laboratory incubations vs. field studies) was not significant (Table 1), thus data from both study types were analyzed together except for those categorical variables not relevant to the laboratory incubations (i.e., level of

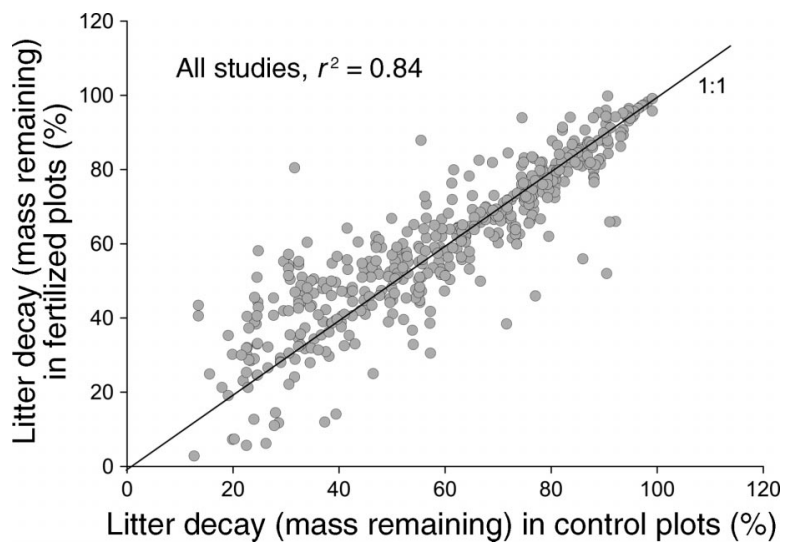

FIG. 1. Relationship between litter decay in fertilized compared to control plots. Each point represents a single comparison between the fertilized and control treatment for a given field experiment or laboratory incubation. Values falling on the 1:1 line indicate a similar decay response for fertilized vs. control treatments, whereas points above or below this line indicate a stimulation or inhibition in decomposition, respectively.

ambient $\mathrm{N}$ deposition, litterbag mesh size, mean annual temperature and precipitation).

The overall effect of $\mathrm{N}$ additions on litter decomposition was not significantly different from zero because of significant variation among studies (Table 1 and Fig. 1). The application rate and type of $\mathrm{N}$ fertilizer applied, the amount of ambient $\mathrm{N}$ deposition (field studies only), litter quality, and the length of time over which litter mass loss was measured all influenced the direction and degree of the litter decay response (Table 1, Figs. 2 and 3). Decomposition showed a small, but significant inhibition $(-5 \%)$ in response to $\mathrm{N}$ additions $<75 \mathrm{~kg} \cdot \mathrm{ha}^{-1} \cdot \mathrm{yr}^{-1}$, a significant stimulation $(+17 \%)$ for additions of $75-125 \mathrm{~kg} \cdot \mathrm{ha}^{-1} \cdot \mathrm{yr}^{-1}$, and a significant inhibition $(-9 \%)$ at $\mathrm{N}$ addition rates $>125 \mathrm{~kg} \cdot \mathrm{ha}^{-1} \cdot \mathrm{yr}^{-1}$ (Fig. 2b). When the $\mathrm{N}$ addition rate was expressed relative to the ambient $\mathrm{N}$-deposition level (possible for field studies only), $\mathrm{N}$ fertilization significantly inhibited litter decay by $8-16 \%$ for sites where $\mathrm{N}$ addition rates were 2-20 times greater than depositional inputs (Fig. 2c). At none of the sites was $\mathrm{N}$ applied at rates less than double the ambient $\mathrm{N}$ deposition level. When $\mathrm{N}$ additions were greater than 20 times the ambient $\mathrm{N}$ deposition level, litter decay was significantly stimulated $(+17 \%)$. The rate of atmospheric $\mathrm{N}$ deposition at the field sites included in our analysis ranged from 0.1 to $19 \mathrm{~kg} \mathrm{~N} \cdot \mathrm{ha}^{-1} \cdot \mathrm{yr}^{-1}$. Nitrogen fertilization rates for these experiments ranged from 24 to $600 \mathrm{~kg}$ $\mathrm{N} \cdot \mathrm{ha}^{-1} \cdot \mathrm{yr}^{-1}$, representing $\mathrm{N}$ additions that exceeded ambient $\mathrm{N}$ depositional inputs at a given site by $2.3-$ 1000 times. This raises the question as to whether the very high rates of fertilization used in some studies are realistic in terms of evaluating the impacts of current or even future $\mathrm{N}$-deposition levels on litter decay. We suggest that the significant stimulation of litter decay 
FIG. 2. Response of litter mass remaining to $\mathrm{N}$ additions expressed as the average percentage change from zero with $95 \%$ confidence intervals for (a) all laboratory and field studies combined, (b) categories of $\mathrm{N}$ fertilization $\left(\mathrm{kg} \cdot \mathrm{ha}^{-1} \cdot \mathrm{yr}^{-1}\right)$, (c) categories of $\mathrm{N}$ addition rates relative to $\mathrm{N}$ deposition for field experiments ( $\mathrm{N}$ additions were $<5$ to $>20$ times that of the ambient $\mathrm{N}$ deposition level), and (d) categories of $\mathrm{N}$ deposition $\left(\mathrm{kg} \cdot \mathrm{ha}^{-1} \cdot \mathrm{yr}^{-1}\right)$ for field experiments. Only those studies where ambient $\mathrm{N}$ deposition was reported or could be obtained from another source were included $(k=323$ total observations). The number of effect-size comparisons, $k$, for each response variable is shown in parentheses.

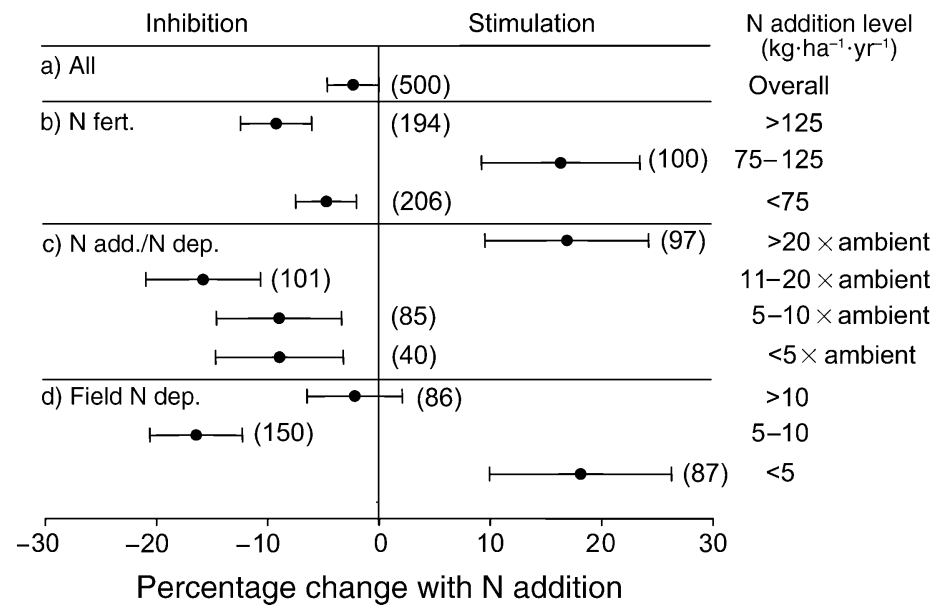

observed for high $\mathrm{N}$-fertilization rates (>20 times ambient $\mathrm{N}$ deposition) is unlikely to be seen in the field under current ambient $\mathrm{N}$ deposition rates, except for high quality litters that exhibited decay stimulation regardless of $\mathrm{N}$ fertilization level (see below for further discussion on litter quality).

There was significant between-group heterogeneity $\left(Q_{\mathrm{b}}\right)$ for fertilizer type (Table 1). Additions of $\mathrm{NH}_{4} \mathrm{NO}_{3}$ significantly inhibited litter decay $(-9 \%)$, urea alone had no significant effect, and $\mathrm{NH}_{4} \mathrm{NO}_{3}$ plus urea significantly stimulated decay $(+23 \%)$. However, there was no significant difference in decay response between litters treated with $\mathrm{NH}_{4} \mathrm{NO}_{3}$ or urea only (data not shown). Additionally, all of the data in the $\mathrm{NH}_{4} \mathrm{NO}_{3}-$ plus-urea category were derived from two studies conducted in Hawaii using Metrosideros polymorpha litter (Hobbie 2000, Hobbie and Vitousek 2000). Thus something other than fertilizer type may account for the observed stimulation of litter decay for these data. We therefore do not have strong evidence that fertilizer type influenced the decay response to $\mathrm{N}$ additions for the studies included in our analysis.

There has been little consideration given in the literature as to how site-specific differences in anthropogenic $\mathrm{N}$ deposition might influence the outcome of $\mathrm{N}$-addition experiments. In this study we observed significant between-group heterogeneity among field sites receiving differing levels of ambient $\mathrm{N}$ deposition (Table 1, Fig. 2d). At sites receiving low levels of ambient $\mathrm{N}$ deposition $\left(<5 \mathrm{~kg} \mathrm{~N} \cdot \mathrm{ha}^{-1} \cdot \mathrm{yr}^{-1}\right)$, additional fertilization significantly stimulated litter decay by $18 \%$. At higher levels of ambient $\mathrm{N}$ deposition, fertilization inhibited mass loss, although only significantly for intermediate amounts of deposition (16\% inhibition for $\left.5-10 \mathrm{~kg} \mathrm{~N} \cdot \mathrm{ha}^{-1} \cdot \mathrm{yr}^{-1}\right)$. In areas exposed to chronic, high levels of ambient $\mathrm{N}$ deposition, the rates of litter decay were likely already altered prior to experiment initiation due to changes in leaf chemistry and the decomposer community. Additional $\mathrm{N}$ additions, therefore, did not translate into significant differences in decay between control and treated litters. Background levels of atmospheric $\mathrm{N}$ inputs need to be considered before establishment of future $\mathrm{N}$-addition studies and in the interpretation of data from ongoing experiments.

Numerous studies have demonstrated that external $\mathrm{N}$ availability and litter quality interact to influence decay dynamics. Nitrogen additions often increase mass loss for litter materials with low lignin content, while inhibiting decay of high-lignin litters (Berg 1986, Berg and Matzner 1997, Carreiro et al. 2000, Sinsabaugh et al. 2002; but see Hobbie and Vitousek [2000] for an exception). Our meta-analysis indicates that, on average, $\mathrm{N}$ additions stimulated the decomposition of high-quality litters by $2 \%$, while reducing mass loss of low-quality litters by $5 \%$ (Fig. 3b). Additionally, mass loss of litters decomposing for less than 24 months was stimulated by up to $7 \%$, while litters that had been

TABLE 1. Effect of $\mathrm{N}$ additions on between-group heterogeneity $\left(Q_{\mathrm{b}}\right)$ for litter mass remaining.

\begin{tabular}{lcc}
\hline \hline \multicolumn{1}{c}{ Categorical variable } & $k \dagger$ & $Q_{\mathrm{b}}$ \\
\hline Study type (laboratory vs. field) & 500 & 0.21 \\
Rate of N addition $\left(\mathrm{kg} \cdot \mathrm{ha}^{-1} \cdot \mathrm{yr}^{-1}\right)$ & & \\
$\quad$ All studies & 500 & $4.35^{* * *}$ \\
$\quad$ Field experiments $\ddagger$ & 323 & $5.98^{* *}$ \\
Fertilizer type $\S$ & 483 & $5.24^{* *}$ \\
Ambient N deposition $\left(\mathrm{kg} \cdot \mathrm{ha}^{-1} \cdot \mathrm{yr}^{-1}\right) \|$ & 323 & $6.51^{* *}$ \\
Litter decay period (months) & 500 & $4.34^{* *}$ \\
Litter quality (low, medium, or high) & 488 & $0.41^{*}$ \\
Litterbag mesh size (mm $\left.{ }^{2}\right) \|$ & 386 & 0.11 \\
Mean annual temperature $\left({ }^{\circ} \mathrm{C}\right) \|$ & 386 & 0.10 \\
Mean annual precipitation $(\mathrm{mm}) \|$ & 386 & 0.35 \\
\hline
\end{tabular}

$* P<0.05 ; * * P<0.01$.

$\dagger$ The number of mean comparisons within each level of analysis is denoted by $k$.

$\$$ Rate of $\mathrm{N}$ additions relative to ambient $\mathrm{N}$ deposition for field experiments. Categories were $<5,5-10,11-20$, and $>20$ times ambient $\mathrm{N}$ deposition. Several studies had to be excluded because the level of $\mathrm{N}$ deposition was not available for those sites.

$\S$ Data were excluded from the analysis if the $\mathrm{N}$ source was unique to that study (i.e., $k=1$ ).

$\|$ Applicable to field studies only. 


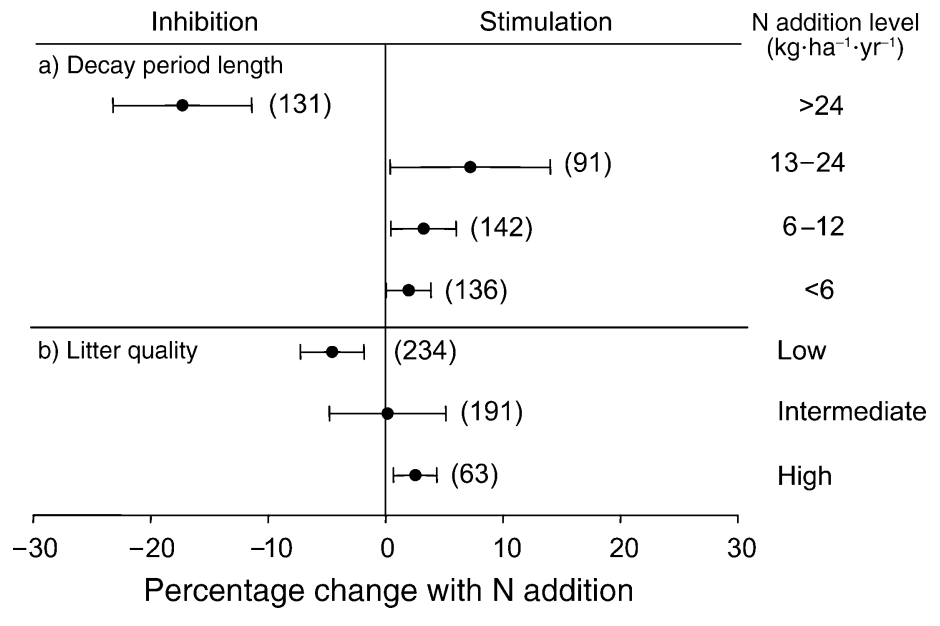

FIG. 3. Response of litter mass remaining to $\mathrm{N}$ additions when the data were grouped by (a) the length of the litter decay period (in months), and (b) initial litter quality (low, intermediate, high). The data are expressed as the mean percentage change from zero with $95 \%$ confidence intervals. The number of effect-size comparisons, $k$, for each response variable is shown in parentheses. decomposing for greater than 24 months exhibited an $18 \%$ decay inhibition (Fig. 3a). This result is consistent with the observation that cellulose rapidly declines, while lignin often accumulates in litter during the later stages of decomposition leading to increasingly lower litter quality over time (McClaugherty and Berg 1987, Magill and Aber 2000).

Litterbag mesh size varied among field studies from 0.15 to $4.5 \mathrm{~mm}^{2}$. Mesh size is known to influence decomposition rates through exclusion of microarthropods that accelerate litter fragmentation (Vossbrinck et al. 1979, Seastedt and Crossley 1980, Bryant et al. 1998). We therefore anticipated that variation in litterbag mesh size might influence the litter decay response to $\mathrm{N}$ additions. However, between-group heterogeneity was not significant for mesh size categories (Table 1), indicating that mesh size did not interact with $\mathrm{N}$ additions to influence litter decay. If the "litterbag effect" modified mass loss rates in some way, it apparently impacted $\mathrm{N}$-treated and control (untreated) litters equally.

The field sites included in our analysis spanned arctic, temperate, and tropical climatic regimes. Given the strong influence of temperature and precipitation on litter decomposition rates in general (reviewed by Coûteaux et al. [1995]), we expected mean annual precipitation and temperature to interact with external $\mathrm{N}$ availability to significantly influence the litter decay response. On the contrary, between-group heterogeneity for these two categorical variables was not significant (Table 1). Thus climate, at least when temperature and precipitation are averaged on an annual basis, does not appear to be an important factor regulating the effect of $\mathrm{N}$ enrichment on litter decomposition. Data reported in the individual studies or available from other sources were insufficient to calculate an integrated climate variable for each site (e.g., AET, actual evapotranspiration sensu Meentemeyer [1978]).

In summary, our results indicate that $\mathrm{N}$ fertilization can alter rates of litter decay, but the direction and degree of response are mediated by interactions between fertilization rates, ambient $\mathrm{N}$ deposition, and litter quality. Litter decomposition was inhibited by $\mathrm{N}$ additions when fertilization rates were 2-20 times the anthropogenic $\mathrm{N}$ deposition level, when ambient $\mathrm{N}$ deposition was $5-10 \mathrm{~kg} \mathrm{~N} \cdot \mathrm{ha}^{-1} \cdot \mathrm{yr}^{-1}$, or when litter quality was low (typically high-lignin litters). Decomposition was stimulated at high fertilization rates $(>20$ times the ambient $\mathrm{N}$ deposition level), at field sites exposed to low ambient $\mathrm{N}$ deposition $\left(<5 \mathrm{~kg} \mathrm{~N} \cdot \mathrm{ha}^{-1} \cdot \mathrm{yr}^{-1}\right)$, and for high-quality litters (low lignin) decomposed in either the field or laboratory. The level of ambient $\mathrm{N}$ deposition at a given field site is important in that it influences how additional $\mathrm{N}$ fertilization will impact the decay process. Litter decay at sites exposed to longterm, high levels of ambient $\mathrm{N}$ deposition may not be as responsive to additional $\mathrm{N}$ inputs compared to less heavily impacted ecosystems.

\section{ACKNOWLEDGMENTS}

This work was supported by a National Science Foundation grant (DEB-0224917) to S.D. Frey. Special thanks to H.W. Hunt for providing information on litter composition.

\section{Literature Cited}

Aber, J. D., and J. M. Melillo. 1982. Nitrogen immobilization in decaying hardwood leaf litter as a function of initial nitrogen and lignin content. Canadian Journal of Botany 60:2263-2269.

Aber, J. D., J. M. Melillo, and C. A. McClaugherty. 1990. Predicting long-term patterns of mass loss, nitrogen dynamics, and soil organic matter formation from initial fine litter chemistry in temperate forest ecosystems. Canadian Journal of Botany 68:2201-2208.

Berg, B. 1986. The influence of experimental acidification on nutrient release and decomposition rates of needle and root litter in the forest floor. Forest Ecology and Management 15:195-213.

Berg, B., and E. Matzner. 1997. Effect of $\mathrm{N}$ deposition on decomposition of plant litter and soil organic matter in forest systems. Environmental Review 5:1-25.

Bryant, D. M., E. A. Holland, T. R. Seastedt, and M. D. Walker. 1998. Analysis of litter decomposition in an alpine tundra. Canadian Journal of Botany 76:1295-1304. 
Carreiro, M. M., R. L. Sinsabaugh, D. A. Repert, and D. F. Parkhurst. 2000. Microbial enzyme shifts explain litter decay responses to simulated $\mathrm{N}$ deposition. Ecology 81:23592365.

Coûteaux, M., P. Bottner, and B. Berg. 1995. Litter decomposition, climate, and litter quality. Trends in Ecology and Evolution 10:63-66.

Curtis, P. S., and X. Z. Wang. 1998. A meta-analysis of elevated $\mathrm{CO}_{2}$ effects on woody plant mass, form, and physiology. Oecologia 113:299-313.

Dijkstra, F. A., S. E. Hobbie, J. M. H. Knops, and P. B. Reich. 2004. Nitrogen deposition and plant species interact to influence soil carbon stabilization. Ecology Letters 7:11921198.

Fog, K. 1988. The effect of added $\mathrm{N}$ on the rate of decomposition of organic matter. Biological Reviews 63:433462.

Frey, S. D., M. Knorr, J. L. Parrent, and R. T. Simpson. 2004. Chronic $\mathrm{N}$ enrichment affects the structure and function of the soil microbial community in temperate hardwood and pine forests. Forest Ecology and Management 196:159171.

Gurevitch, J., and L. V. Hedges. 1993. Meta-analysis: combining the results of independent experiments. Pages 378398 in S. M. Scheiner and J. Gurevitch, editors. Design and analysis of ecological experiments. Chapman and Hall, New York, New York, USA.

Gurevitch, J., L. L. Morrow, A. Wallace, and J. S. Walsh. 1992. A meta-analysis of competition in field experiments. American Naturalist 140:539-572.

Hedges, L. V., and I. Olkin. 1985. Statistical methods for meta-analysis. Academic Press, New York, New York, USA.

Hobbie, S. E. 2000. Interactions between litter lignin and soil $\mathrm{N}$ availability during leaf litter decomposition in a $\mathrm{Ha}$ waiian montane forest. Ecosystems 3:484-494.

Hobbie, S. E., and P. M. Vitousek. 2000. Nutrient limitation of decomposition in Hawaiian forests. Ecology 81:18671877.

Hunt, H. W., E. R. Ingham, D. C. Coleman, E. T. Elliot, and C. P. P. Reid. 1988. N limitation of production and decomposition in prairie, mountain meadow, and pine forest. Ecology 69:1009-1016.

Jablonski, L. M., X. Wang, and P. S. Curtis. 2002. Plant reproduction under elevated $\mathrm{CO}_{2}$ conditions: a meta-analysis of reports on 79 crop and wild species. New Phytologist 156:9-26.

Johnson, D. W., and P. S. Curtis. 2001. Effects of forest management on soil $\mathrm{C}$ and $\mathrm{N}$ storage: meta analysis. Forest Ecology and Management 140:227-238.

Magill, A. H., and J. D. Aber. 1998. Long-term effects of experimental $\mathrm{N}$ additions on foliar litter decay and humus formation in forest ecosystems. Plant and Soil 203:301311.

Magill, A. H., and J. D. Aber. 2000. Dissolved organic carbon and $\mathrm{N}$ relationships in forest litter as affected by $\mathrm{N}$ deposition. Soil Biology and Biochemistry 32:603-613.

McClaugherty, C., and B. Berg. 1987. Cellulose, lignin, and $\mathrm{N}$ concentrations as rate regulating factors in late stages of forest litter decomposition. Pedobiologia 30:101-112.

Meentemeyer, V. 1978. Macroclimate and lignin control of litter decomposition rates. Ecology 59:465-472.

Melillo, J. M., J. D. Aber, and F. F. Muratore. 1982. Nitrogen and lignin control of hardwood leaf litter decomposition dynamics. Ecology 63:621-626.

Norby, R. J., K. Ogle, and P. S. Curtis. 2001. Aboveground growth and competition in forest gap models: an analysis for studies of climatic change. Climatic Change 51(3-4): 415-447.

Olson, J. S. 1963. Energy storage and the balance of producers and decomposers in ecological systems. Ecology 44: 322-331.

Parton, W. J., D. S. Schimel, C. V. Cole, and D. S. Ojima. 1987. Analysis of factors controlling soil organic matter levels in Great Plains grasslands. Soil Science Society of America Journal 51:1173-1179.

Pastor, J., M. A. Stillwell, and D. Tilman. 1987. Little bluestem litter dynamics in Minnesota old fields. Oecologia 72: 327-330.

Prescott, C. E. 1995. Does $\mathrm{N}$ availability control rates of litter decomposition in forests? Plant and Soil 168-169:8388.

Rosenberg, M. S., D. C. Adams, and J. Gurevitch. 1997. Meta Win. Statistical software for meta- analysis with resampling tests. Sinauer Associates, Sunderland, Massachusetts, USA.

Rustad, L. E., J. L. Campbell, G. M. Marion, R. J. Norby, M. J. Mitchell, A. E. Hartley, J. H. C. Cornelissen, J. Gurevitch, and GTCE News. 2001. A meta-analysis of the response of soil respiration, net $\mathrm{N}$ mineralization, and aboveground plant growth to experimental ecosystem warming. Oecologia 126:543-562.

Seastedt, T. R., and D. A. Crossley. 1980. Effects of microarthopods on the seasonal dynamics of nutrients in forest litter. Soil Biology and Biochemistry 12:333-342.

Sinsabaugh, R. L., M. M. Carreiro, and D. A. Repert. 2002. Allocation of extracellular enzymatic activity in relation to litter composition, $\mathrm{N}$ deposition, and mass loss. Biogeochemistry 60:1-24.

Taylor, B. R., D. Parkinson, and W. F. J. Parsons. 1989. Nitrogen and lignin content as predictors of litter decay rates: a microcosm test. Ecology 70:97-104.

Vossbrinck, C. R., D. C. Coleman, and T. A. Woolley. 1979. Abiotic and biotic factors in litter decomposition in a semiarid grassland. Ecology 60:265-271.

\section{APPENDIX A}

References for the 24 studies included in our meta-analysis database, along with study location and the type of litter used, are available in ESA's Electronic Data Archive: Ecological Archives E086-177-A1.

\section{APPENDIX B}

Site and soil characteristics in the 24 studies are available in ESA's Electronic Data Archive: Ecological Archives E086177-A2.

\section{APPENDIX C}

A list of studies providing data for each subdivision of the categorical variables is available in ESA's Electronic Data Archive: Ecological Archives E086-177-A3. 